ISSN: 2643-6736

\title{
Robotic Farmers in Agriculture
}

\author{
Manu Mitra* \\ Department of Electrical Engineering, Alumnus of University of Bridgeport, Bridgeport, United States
}

*Corresponding author: Manu Mitra, Department of Electrical Engineering, Alumnus of University of Bridgeport, Bridgeport, United States

Published: 㠿 March 12, 2019

\section{Introduction}

Revolution of Robotic farmer is on the way, fruit picking machines are ready to roll into the fields and will replace human workers at one point of time. A Robot Farmer is just a one of the new technologies that will completely transform agriculture sector. Today's agricultural technology helps farmers to plow and spray crops. In an improved automation and big data analytics with farming robot technology are pointing out to big benefits. Goldman Sachs estimates precision farming - the combination of agriculture and technology could be around $\$ 240$ billion market by 2050 . As per Euro monitor intersection of robotics, artificial intelligence, analytics and machines for precision farming is one of the top industry's top opportunities. In Europe, Spanish company called Agrobot has developed a strawberry farming robot. It uses up to 24 robotic arms to pick fruit and is capable of autonomous navigation. In England, Dogtooth Technologies are developing its own series of autonomous robots capable of picking fruit. Dogtooth machines are proficient enough of autonomous navigation, locating and picking ripe fruit and grading its quality [1] (Figure 1).

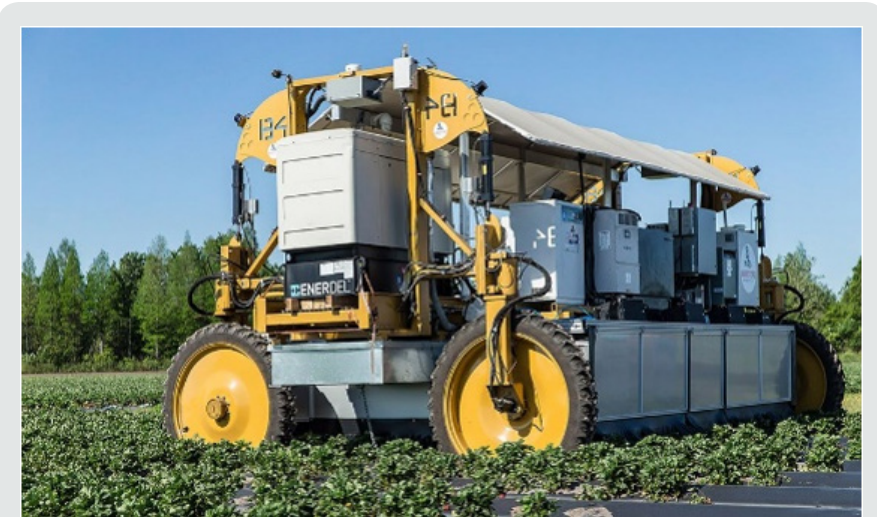

Figure 1: Illustrates Harvesting CROO's machine is headed for farms in Florida and California. Image Credit: Image courtesy of Harvest CROO Robotics [1].

\section{Robotic Weeders}

The increasing recognition of robotic weeders for specialty crops has grown - Specialty crops are vegetables like lettuce, broccoli, tomatoes and onions. These are not produced in mass like corn, soybeans and wheat. The reason for robotic weeders steams from two major issues. One is a deficiency of herbicides available for usage in specialty crops. Another issue; as a matter of fact hand-weeding has become more and more expensive. Without pesticides, growers have had to hire people to hand-weed vast fields. Hand weeding is very slow and increasing expensive, it can cost around $\$ 150-\$ 30$ per acre. That is one of the reasons some people look to robotic weeders. The robotic weeders are programmed to recognize a pattern and can differentiate between a plant and the soil. Although, they currently are having trouble to differentiate between a weed and a crop. The robotic weeders in the market cost between $\$ 120,000$ and $\$ 175,000$, it is a better longterm option than expensive hand weeding. Fennimore considers that robotic weeders are the future of weeding for specialty crops. The reason because of higher labor costs and more incentives to grow organically with less pesticides. European growers have been using robotic weeders for a while [2] (Figure 2).

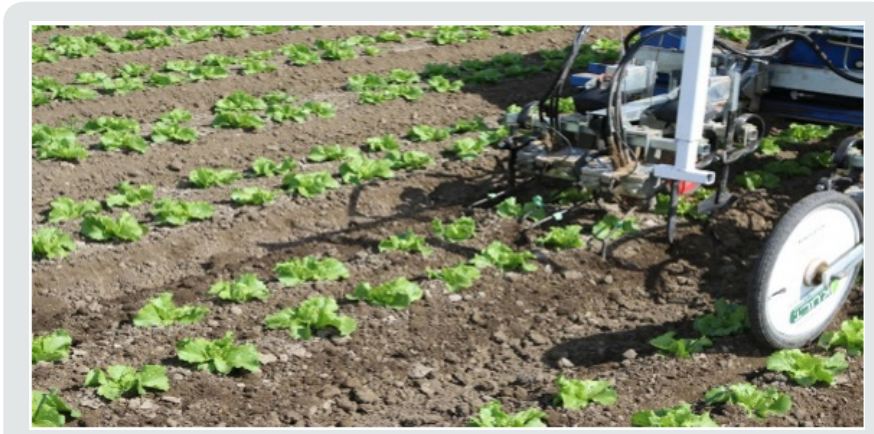

Figure 2: Illustrates robotic weeder is operating in a field near Santa Maria, CA. Image Credit: Image courtesy of Steven Fennimore [2]. 


\section{Harvesting Cucumbers Through Robots}

In automation areas for instance, automotive industry are not the only ones to depend on robots. In agriculture, automation systems are surpassing strenuous manual labor. As a project, the Fraunhofer Institute for Production Systems and Design Technology developed and tested a dual arm robotic system for automated harvesting of cucumbers. In Germany, cucumbers are ordained for pickles that are harvested with the aid of "cucumber flyers" - a farm vehicles with wing like add-ons. Many of the country's agricultural regions subsequently face an uncertain future; cucumber farming has already begun moving to Eastern Europe and India. Thus, there is a pressing requirement for improved harvesting technologies to maintain economic viability of cucumber farming in Germany. Experts developed a dual arm robot system consisting of inexpensive light modules. This system is used for automated cucumber farming and other agricultural applications. This Robotic cucumber picker is cost effective, high performance and dependable. Even in adverse weather, it is capable of first identifying ripe cucumbers and then using its two gripper arms to gently pick and store them. This novel method can also make it possible for to imitate human movements. Scientist want to make sure that it does not damage crops or pull to their roots out of the soil. This robotic cucumber harvester is as efficient as its experienced human counterpart, who can pick as many as 13 cucumbers per minute. Cucumber farmers and agricultural associations have expressed significant interest in the dual arm robot [3] (Figure 3).

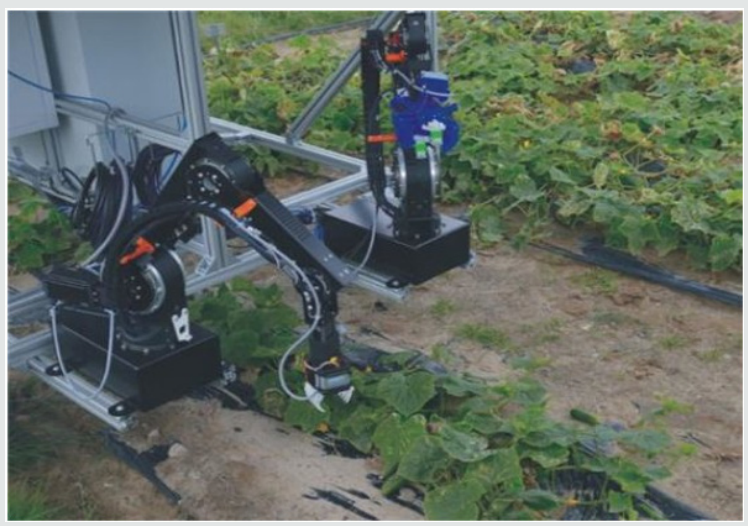

Figure 3: Illustrates prototype of the dual-arm robot system during the first field tests. Image Credit: Fraunhofer IPK [3]

\section{Harvesting Broccoli using Robots}

This Project was jointly funded by BBSRC and create improvements in United Kingdom; in this 3D camera technology was used to recognize and select whether broccoli is ready for collecting. It is the key step towards the development of an automatic robotic harvesting system for broccoli, which will not only considerably decrease production costs but also decrease amount of labor cost. This project also addresses challenges associated with recognition, deterrence and management of disease by creating diagnostic tools for farm use and substitute to chemical pesticides. This will allow the major producers in these industries to rapidly analyze the existence of disease and enable earlier decision making. It is also expected that this development of project will create long-needed substitute to use of pesticides by mushroom and potato industries therefore ensuring future sustainability [4] (Figure 4).

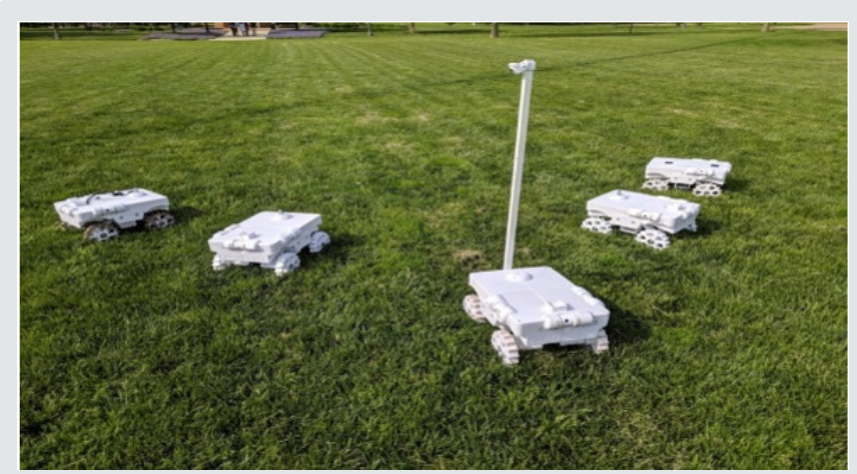

Figure 4: Illustrates the TerraSentia robot that autonomously monitors crops earned the best systems paper award at Robotics: Science and Systems, the preeminent robotics conference held in Pittsburgh. Image Credit: TERRA-MEPP Project [6].

\section{Counting Crop Using Robots}

Crop breeders run large scale of trials comparing thousands of varieties of crops over hundreds of acres and measure key qualities, for instance emergence of plant, height, by hand. This task is expensive, inaccurate, time consuming and completely inadequate; team can only measure these manually by fraction of plants in a field. TerraSentia is a compact transportable robot weight about 24 pounds and 13 inch wide. It can capture each plant from to bottom using advanced suite of cameras, deep learning and complex algorithms. Using a method called learning method, experts taught TerraSentia to count corn plants with just 300 images. It is a TERRA-MEPP research task that is low cost phenotyping robot to recognize top performing crops. This research was controlled by the University of Illinois in collaboration with Cornell University and Signetron with sustenance from Advanced Research Project Agency - Energy [5,6].

\section{Combatting Weeds by Laser Robots}

Farmers who want rich harvest and need to drive weeds so that crops can cultivate better. In organic agriculture - herbicides are not considered as they are toxic chemicals and only unwanted plants should be arduously weeded out. This time-consuming work are taken care of laser robots. Computer Experts in Photogrammetry at University of Bonn have developed a new system using advanced cameras on all terrain robot vehicle or tractor add-on and unwanted wild weeds are automatically identified in various crops and taken out. Scientists are moving forward for their startup to develop the business plan for this novel technology and also working to buy the parts required for the project to construct a prototype. At University 
of Bonn, Chamber of Commerce and Industry, both founders won an award for the best novel technology. "The aim is to contribute in achieving more sustainable agriculture. The robot fires the leaves of unnecessary plants in the crops with short laser pulses, which weakens in their strength" [7].

\section{Acknowledgment}

Author would like to thank Prof. Navarun Gupta, Prof. Hassan Bajwa, Prof. Linfeng Zhang and Prof. Hmurcik for their academic support. Author also thanks anonymous reviewers for their comments.

\section{References}

1. Larkin M (2018) Labor Terminators: Farming Robots Are About to take Over Our Farms.
2. American Society of Agronomy (2018) Robotic weeders: To a farm near you? Technology provides alternative to herbicides, hand-weeding. ScienceDaily.

3. Fraunhofer-Gesellschaft (2018) Lightweight robots harvest cucumbers. ScienceDaily.

4. University of Lincoln (2015) Robotic harvesting of broccoli could be coming to a field near you. ScienceDaily.

5. Erkan Kayacan, Sierra N Young, Joshua M Peschel, Girish Chowdhary (2018) High-precision control of tracked field robots in the presence of unknown traction coefficients. Journal of Field Robotics 35(7): 10501062.

6. Carl R Woese Institute for Genomic Biology, University of Illinois at Urbana-Champaign (2018) Crop-counting robot. ScienceDaily.

7. Universität Bonn (2017) Combatting weeds with lasers. ScienceDaily.

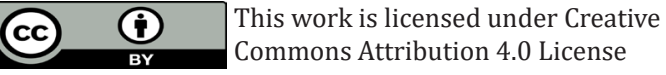

To Submit Your Article Click Here: Submit Article

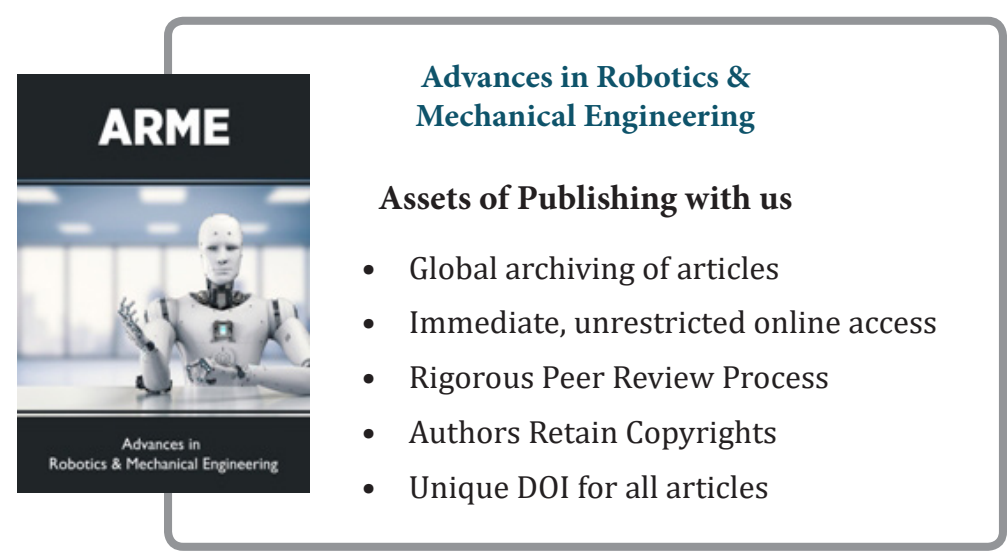

